\title{
INTERAÇÕES ESPÉCIE-AMBIENTE NA COLONIZAÇÃO DE UMA VOÇOROCA EM ITUMIRIM, MINAS GERAIS
}

\author{
Ricardo Ayres Loschi ${ }^{1}$, José Aldo Alves Pereira², Evandro Luiz Mendonça Machado ${ }^{3}$, Leandro Carlos $^{4}$, \\ João José Granate de Sá e Melo Marques ${ }^{5}$
}

(recebido: 11 de dezembro de 2009; aceito: 28 de janeiro de 2011)

\begin{abstract}
RESUMO: Objetivou-se, com este trabalho, conhecer e avaliar a estrutura das espécies em regeneração numa voçoroca em Itumirim, MG (2 $1^{\circ} 16^{\prime} \mathrm{S}$ e $\left.44^{\circ} 50^{\prime} \mathrm{W}\right)$ e verificar a influência dos fatores edáficos na distribuição e na ocorrência das espécies. A voçoroca possui uma área de 0,9 ha e foi subdividida em três setores denominados como braços "A"; "B" e "C". Para o levantamento estrutural da vegetação, foi empregado o método de agulha, sendo amostrados 574 pontos distribuídos sistematicamente pelos três braços. Cada ponto foi estratificado no terreno em função de um gradiente topográfico. Para a obtenção das variáveis ambientais (análises físicoquímica, compactação e umidade dos solos), foram determinados 119 pontos de coletas de solos localizados paralelos as transeções do levantamento estrutural. Observou-se, nos três braços, um predomínio de solos/sedimentos com altos teores de areia e com baixa fertilidade. De maneira geral, a ordenação das espécies pela CCA na voçoroca mostrou que as espécies do grupo das "graminóides" tendem a ser mais abundantes nas áreas mais baixas, úmidas e relativamente mais férteis, ocorrendo o contrário para as espécies do grupo das "samambaias", já que estas se tornaram mais abundantes à medida que houve uma ascensão topográfica com a consequente redução da umidade e aumento do adensamento do solo. Observou-se que a grande maioria das espécies de hábito arbustivo-arbóreo não apresentou importantes correlações com as principais variáveis ambientais utilizadas na CCA.
\end{abstract}

Palavras-chave: Erosão, regeneração natural, método de agulha, relações espécie-ambiente, análise multivariada.

\section{SPECIES-ENVIRONMENT INTERACTIONS IN THE COLONIZATION OF A GULLY IN ITUMIRIM, MINAS GERAIS}

\begin{abstract}
This work aimed to identify and evaluate the structure of regenerating species in a gully of Itumirim, MG (21 ${ }^{\circ} 16^{\prime} S$ and $44^{\circ} 50^{\prime} W$ ) and to verify the influence of edaphic factors on the distribution and occurrence of species. The gully in question covers an area of 0.9 ha and was divided into three sections, namely ' $A$ ', ' $B$ ' and ' $C$ ' arms. For the structural survey of vegetation the needle method was used, whereby 574 points systematically distributed across the three arms were sampled. Each point was stratified on the terrain as a function of a topographic gradient. In order to obtain environmental variables (physicochemical analysis, soil moisture and compaction), 119 soil collection points were defined, parallel with the transects of the structural survey. A prevalence of soils/sediments with high sand content and low fertility was observed in all three arms. Overall, species ordination in the gully through CCA showed that species in the 'grass-like' group tend to be more abundant in low, humid, relatively more fertile areas, whereas species in the 'fern' group tend to be more abundant in higher topographic positions where soil moisture is reduced and compaction increases. The vast majority of shrub and tree life forms failed to present significant correlations with the main environmental variables used in the CCA.
\end{abstract}

Key words: Erosion, natural regeneration, needle method, species-environment interactions, multivariate analysis.

\section{INTRODUÇÃO}

Na Bacia do Alto Rio Grande, região de estudo, o problema da erosão assume proporções alarmantes, sendo a paisagem caracterizada pela intensa presença de voçorocas, o que gera problemas de ordem ambiental, econômica e social (SILVA et al., 1993). A erosão e as questões associadas não são apenas problemas locais, mas ameaças a bacias hidrográficas inteiras (ARAUJO et al., 2005).

A erosão do solo é um fenômeno que tem preocupado o homem nas últimas décadas, despertando

\footnotetext{
${ }^{1}$ Engenheiro Florestal, Mestre em Engenharia Florestal - Departamento de Ciências Florestais/DCF - Universidade Federal de Lavras/UFLA Cx. P. 3037 - 37200-000 - Lavras, MG - riloschi@ gmail.com

${ }^{2}$ Engenheiro Florestal, Professor Dr. em Ecologia - Departamento de Ciências Florestais/DCF - Universidade Federal de Lavras/UFLA Cx. P. 3037 - 37200-000 - Lavras, MG - j.aldo@dcf.ufla.br

${ }^{3}$ Engenheiro Florestal, Professor Dr. em Ecologia - Departamento de Engenharia Florestal/DEF - Universidade Federal dos Vales do Jequitinhonha e Mucuri/UFVJM - Cx. P. 049 - 39100-000 - Diamantina, MG - machadoelm@gmail.com

${ }^{4}$ Engenheiro Florestal, Doutorando em Engenharia Florestal - Departamento de Ciências Florestais/DCF - Universidade Federal de Lavras/UFLA Cx. P. 3037 -37200-000 - Lavras, MG - lcmaestro@gmail.com

${ }^{5}$ Engenheiro Agrônomo, Professor Dr. em Química do Solo e Pedologia-Departamento de Ciências do Solo/DCS - Universidade Federal de Lavras/UFLACx. P. 3037 -37200-000 Lavras, MG - jmarques@dcs.ufla.br
} 
interesse de pesquisadores no que se refere às causas que levam a sua origem, evolução e controle, em razão desta atingir e inutilizar extensas áreas de terras, levando, até mesmo, a uma descaracterização completa do meio físico. Embora os processos erosivos sejam estudados em vários países, tanto seus mecanismos ativadores, quanto as condições predisponentes, são variáveis e específicos para cada região e dependentes de uma gama de fatores naturais, tais como: clima, condições de relevo, natureza do terreno (substrato rochoso e materiais inconsolidados) e a cobertura vegetal (PEDRO; LORANDI, 2004).

A erosão hídrica é um dos mais ativos processos de degradação ambiental, sobretudo em regiões de clima tropical. A erosão age de forma variada, desde a forma mais sutil, como a laminar, muitas vezes despercebida, até a mais evidente e desastrosa, como a que desenvolve as voçorocas (PARZANESE, 1991). A voçoroca é a forma mais agressiva de erosão, ocasionada por grandes concentrações de enxurrada que passam, ano após ano, no mesmo sulco, que vai se ampliando pelo deslocamento de grandes massas de solo, formando grandes cavidades em extensão e profundidade, sendo de recuperação muito difícil (BAHIA et al., 1992).

Uma das estratégias mais recomendadas em planos de recuperação de áreas degradadas é a reprodução do padrão natural das comunidades vegetais, o que aumenta a probabilidade de sucesso na recuperação ambiental, além de contribuir para reduzir os custos desses projetos (ARAÚJO et al., 2006). A presença da regeneração e o vigor da vegetação dependem, entre outros fatores bióticos e abióticos, da disponibilidade de nutrientes e da umidade do solo, fatores que normalmente se acham em níveis inadequados em áreas erodidas (RESENDE et al., 2007).

Estudos que buscam conhecer os atributos de solo, sua composição florística e as características ecológicas das espécies ocorrentes em ambientes alterados por processos de voçorocamento têm muito a contribuir com programas que visam à conservação, à preservação e à recuperação desses ecossistemas. No entanto, verifica-se que são raros os estudos desenvolvidos e divulgados com esse intuito em voçorocas, merecendo destaque o trabalho realizado por Farias et al. (1993). Com isso, desenvolveuse o presente trabalho em uma voçoroca localizada no município de Itumirim, MG, com os objetivos de conhecer e avaliar a composição florística, a estrutura e a diversidade das espécies em regeneração e verificar a influência dos fatores edáficos na distribuição e ocorrência das espécies regenerantes.

Cerne, Lavras, v. 17, n. 2, p. 161-180, abr./jun. 2011

\section{MATERIAL E MÉTODOS}

\section{1 Área de estudo}

O presente estudo foi conduzido em uma área sob efeito de erosão hídrica severa, conhecida popularmente como voçoroca, localizada no Município de Itumirim/MG. A área estudada encontra-se nas coordenadas de $21^{\circ} 16^{\prime} \mathrm{S}$ e $44^{\circ} 50^{\prime} \mathrm{W}$, com altitude média de $880 \mathrm{~m}$, em uma região de relevo suave. A voçoroca tem uma área de 0,9 ha, que foi subdividida em três setores (Figura 1), os quais serão denominados daqui em diante como braços "A"; "B" e "C". A definição dos mesmos foi realizada tendo como base o nível de atividade erosiva, em que o local "A" é o mais estável, o "B" encontra-se em contínuo avanço e o "C" é intermediário quanto ao padrão de desenvolvimento da atividade erosiva.

As classes de solos predominantes no local são os Latossolos Vermelho-Amarelos e Cambissolos, derivados da alteração do gnaisse-granítico com predominância dos últimos. O clima é de transição entre Cwa e Cwb, de acordo com a classificação climática de Köppen (ANTUNES, 1986), onde Cwa é caracterizado como mesotérmico, com inverno seco e verão chuvoso, no qual a temperatura média do mês mais frio é inferior a $18^{\circ} \mathrm{C}$ e a do mês mais quente é superior a $22^{\circ} \mathrm{C}$, enquanto que no Cwb, a temperatura média do mês mais quente é inferior a $22^{\circ} \mathrm{C}$. Os dados climáticos completos mais próximos são encontrados para o Município de Lavras, MG (21 ${ }^{\circ} 14^{\prime} \mathrm{S}$ e $45^{\circ} \mathrm{W}$, com $918 \mathrm{~m}$ de altitude), onde a temperatura média anual é de $19,4^{\circ} \mathrm{C}$ e a precipitação média anual é de $1.530 \mathrm{~mm}$ (BRASIL, 1992). A vegetação original da região era composta por um mosaico de diferentes fitofisionomias de cerrados e matas (CARVALHO, 1992; QUEIROZ et al., 1980), que foram substituídas por pastagens e culturas agrícolas, restando apenas pequenos fragmentos da vegetação original, geralmente bastante antropizados.

\subsection{Levantamento da regeneração natural}

Para avaliação qualitativa e quantitativa dos elementos regenerantes da vegetação, foi empregado o método de agulha, o qual vem sendo utilizado em investigações de formações herbáceas, pastagens e na descrição dos estratos inferiores em comunidades mais estratificadas (ALMEIDA; ARAÚJO, 1997; BUSELATO; BUENO, 1981; CASTELLANI; STUBBLEBINE, 1993; FRIZZO; PORTO, 2004; MANTOVANI, 1987; SÁ, 1996; VIEIRA; PESSOA, 2001). 


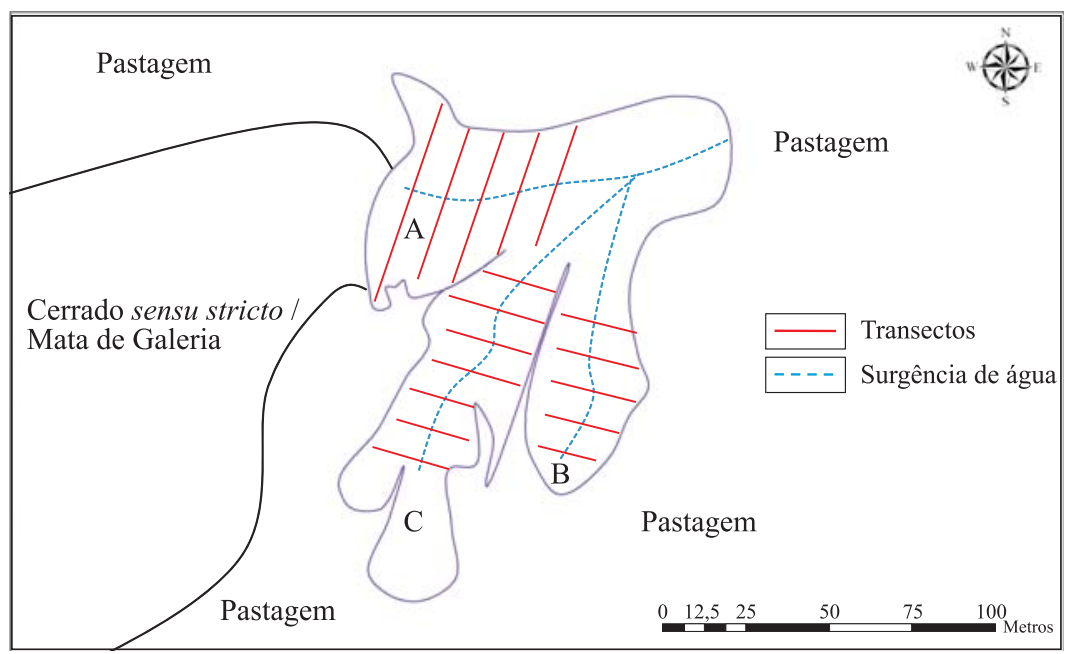

Figura 1 - Mapa mostrando os três braços ("A", "B" e "C") da voçoroca estudada no município de Itumirim, MG, enfatizando a localização dos transectos analisados, a surgência de água e o entorno da área de estudo.

Figure 1 - Map depicting three arms, ' $A$ ', ' $B$ ' and ' $C$ ', of a gully in the municipality of Itumirim, MG, highlighting transects, emerging water and surrounding areas.

Foram amostrados 574 pontos (260 em “A”, 123 em "B" e 191 em "C"). Os pontos foram distribuídos sistematicamente pelos braços em 17 transeções (cinco em "A", cinco em "B" e sete em "C") (Figura 1). Esses transectos foram dispostos de forma a transpor perpendicularmente o braço em seu sentido de maior declividade, do topo passando pelo vale e terminando no topo novamente (Figura 2). As distâncias foram de $10 \mathrm{~m}$ entre transeções e $1 \mathrm{~m}$ entre pontos. Cada ponto foi estratificado segundo sua localização no terreno (Figura 2), divididos em: baixada úmida - "BU" (onde há surgência de água); terço inferior - "TI" (porção do terreno próximo a surgência de água e a mais baixa da encosta);

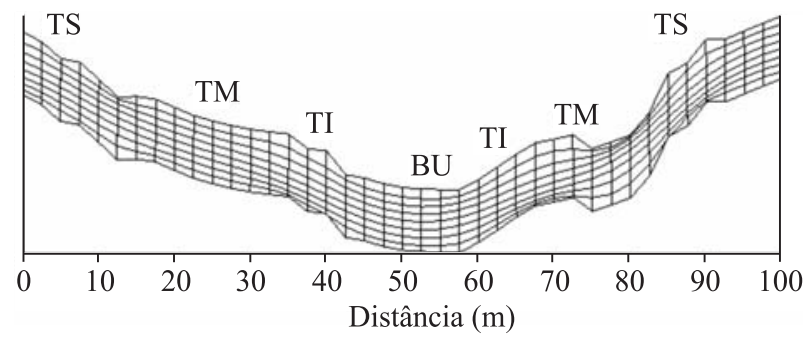

Figura 2 - Diagrama de perfil representando a distribuição dos setores topográficos de uma voçoroca. Em que: $\mathrm{BU}=$ baixada úmida; $\mathrm{TI}=$ terço inferior; $\mathrm{TM}=$ terço médio; $\mathrm{TS}=$ terço superior.

Figure 2 - Profile diagram representing the distribution of topographic sections of a gully, where BU = bottom slack, $T I=$ lower third, $T M=$ middle third, $T S=$ upper third. terço médio - "TM" (porção intermediária da encosta) e terço superior - "TS" (porção mais alta da encosta). Assim, cada transeção possui sete setores, sendo dois terços superiores, dois médios, dois inferiores e uma baixada úmida.

A agulha utilizada possui cerca de $5 \mathrm{~mm}$ de diâmetro e $2 \mathrm{~m}$ de altura e, quando solta verticalmente sobre o solo em cada ponto, são anotadas as espécies tocadas pela mesma e o número de toques. Todos os indivíduos tocados pela agulha, independentemente do seu hábito, foram amostrados. Pontos com solo exposto também foram considerados, entendendo-se aqui solo exposto como ponto sem ocorrência de toque. Como o foco do trabalho está relacionado principalmente com as espécies de hábito arbustivo-arbóreo em regeneração na voçoroca, as espécies pertencentes às famílias botânicas Cyperaceae, Eriocaulaceae, Iridaceae e Poaceae foram todas agrupadas como "ervas graminóides" ou apenas "graminóides", assim como as espécies das famílias Dennstaedtiaceae e Gleicheniaceae (pteridófitas) foram agrupadas como "samambaias". Todas as espécies foram coletadas e identificadas por meio de bibliografia especializada, consulta a especialistas e material de herbário, estando as exsicatas dos materiais depositadas no Herbário ESAL da Universidade Federal de Lavras. As espécies foram classificadas em famílias de acordo com o sistema do Angiosperm Phylogeny Group II (APG, 2003).

Cerne, Lavras, v. 17, n. 2, p. 161-180, abr./jun. 2011 


\subsection{Variáveis ambientais}

Foram determinados 119 pontos de coletas de solos localizados paralelos as transeções do levantamento da regeneração natural, a fim de causar o menor impacto à mesma. Nestes pontos, foram realizadas coletas de solo/ sedimento superficial $(0-20 \mathrm{~cm})$ para as análises químicas, texturais e de umidades, além da avaliação da resistência à penetração nas profundidades de $0-20 \mathrm{~cm}, 20-40 \mathrm{~cm}$ e 40-60 cm.

Para as análises químicas e texturais, foram coletadas amostras compostas de $500 \mathrm{~g}$, sendo estas analisadas pelo Laboratório do Departamento de Ciência do Solo da Universidade Federal de Lavras utilizando-se o protocolo da Empresa Brasileira de Pesquisa Agropecuária - Embrapa (1997). As variáveis obtidas foram: $\mathrm{pH}$ em água, $\mathrm{P}, \mathrm{K}, \mathrm{Ca}$, $\mathrm{Mg}, \mathrm{Al}$, acidez potencial $(\mathrm{H}+\mathrm{Al})$, soma de bases $(\mathrm{SB})$, CTC efetiva (t), CTC potencial (T), saturação por bases (V), saturação por alumínio (m), P remanescente, matéria orgânica (MO), além dos teores de areia, silte e argila.

A determinação do teor de umidade do solo foi realizada por meio do método gravimétrico, que se constitui da coleta e da mensuração do peso úmido e seco das amostras de solo superficial, condicionadas em estufa regulada a uma temperatura de $100-105^{\circ} \mathrm{C}$ por um período de 24 horas (GARDNER, 1986). Esta quantificação foi realizada a intervalos de dois meses durante um período de um ano, sempre no princípio da manhã.

A resistência mecânica do solo à penetração foi obtida por meio da utilização do penetrômetro de impacto, modelo IAA/PLANALSUCAR-STOLF, segundo metodologia preconizada por Stolf et al. (1983). Foram realizadas três repetições em cada ponto. Os cálculos foram realizados com o apoio do programa computacional de Stolf (1991) "PENETRON", sendo que os valores obtidos em Kgf.cm ${ }^{-2}$, foram multiplicados pela constante 0,098 para transformação em unidades MPa. Os solos ocorrentes nos três braços da voçoroca e na área de confluência foram classificados de acordo com o Sistema Brasileiro de Classificação de Solos (EMBRAPA, 2006) até o nível de subgrupo ( $4^{\circ}$ nível categórico).

\subsection{Análise dos dados fitossociológicos e ambientais}

Para cada espécie e em cada setor dos três braços da voçoroca, foram obtidos os seguintes parâmetros fitossociológicos: Média de toques: $\mathrm{MTi}=\mathrm{NTi} / \mathrm{NPi}$; Frequência absoluta: FAi = 100.NPi / NTP; Vigor absoluto: $\mathrm{VAi}=100 . \mathrm{NTi} / \mathrm{NTP}$; Índice de cobertura: $\mathrm{ICi}=\mathrm{FAi}+$ VAi. Onde: $\mathrm{NTi}=\mathrm{N}^{\circ}$ de toques da espécie $\mathrm{i} ; \mathrm{NPi}=\mathrm{N}^{\circ}$ de pontos com a espécie $\mathrm{i}$; NTP $=\mathrm{N}^{\circ}$ total de pontos.
A média de toques (MTi) foi obtida a partir da relação entre o número de vezes que a espécie tocou na agulha e o número de pontos onde a espécie ocorreu. Esse parâmetro indica o número médio de estratos da folhagem de uma espécie cobrindo o solo verticalmente (GOODALL, 1952). A frequência absoluta ou cobertura absoluta (FAi) referese à porcentagem de unidades amostrais com ocorrência de uma determinada espécie (como no método de pontos, o toque da agulha indica a cobertura do ponto por um ou mais indivíduos de uma ou mais espécies, este parâmetro pode expressar tanto a frequência como a cobertura) (MATTEUCCI; COLMA, 1982). O vigor absoluto (VAi) reflete a estratificação ou a cobertura vertical de uma espécie e depende da sua forma de vida e desenvolvimento. Pode ser usado na indicação da dominância ou notabilidade das espécies, seja por sua altura, cobertura ou densidade (MATTEUCCI; COLMA, 1982). Por fim, o índice de cobertura (IC) resulta da soma da frequência absoluta com o vigor absoluto da espécie.

Para a realização de análises das correlações entre as variações ambientais e distribuição das abundâncias das espécies registradas no levantamento estrutural, foram feitas análises de correlação canônica (CCA), para a qual foram preparadas duas matrizes. A primeira matriz utilizada foi obtida a partir dos dados de vegetação encontrados na área. A segunda matriz foi formada a partir dos dados ambientais obtidos das análises físico-química, compactação e umidade dos solos. A CCA correlaciona simultaneamente duas matrizes, uma matriz de abundância de espécies por amostra e uma matriz correspondente de variáveis ambientais, por isto é chamada de análise de gradientes mista. Assim, produz uma ordenação simultânea de espécies, amostras e variáveis ambientais, ou seja, realiza uma análise direta dos gradientes na vegetação. A matriz de variáveis ambientais inclui, inicialmente, todas as variáveis coletadas, e após uma CCA preliminar são eliminadas aquelas que produzem baixas correlações com os eixos de ordenação e também as redundantes entre si. Com isso, após realizar uma CCA preliminar, com as 23 variáveis ambientais estabelecidas inicialmente para cada braço, foram eliminadas aquelas variáveis ambientais fracamente correlacionadas ou altamente redundantes com outras variáveis. Para o braço "A", a CCA final foi processada com as sete variáveis mais representativas e mais fortemente correlacionadas com os eixos de ordenação: saturação por bases $(\mathrm{V}) ; \mathrm{pH}$; umidade máxima (U\% Max) e umidade mínima (U\% Min); resistência do solo à penetração (RP) nas profundidades 0-20 cm (RP1), 20-40 cm (RP2) e 40-60 cm (RP3).

Cerne, Lavras, v. 17, n. 2, p. 161-180, abr./jun. 2011 
Para o braço "B", as variáveis mais representativas e mais fortemente correlacionadas com os eixos de ordenação foram: frações argila e silte, matéria orgânica (MO), CTC efetiva (t) e resistência do solo à penetração (RP) na profundidade $0-20 \mathrm{~cm}$ (RP1). Já para o braço "C", foram: frações areia e silte, umidade máxima (U\% Max) e resistência do solo à penetração $(\mathrm{RP})$ nas profundidades 0-20 cm (RP1), 20-40 cm (RP2) e 40-60 cm (RP3). Para a realização destas análises, foi utilizado o programa PcOrd for Windows, versão 4.14 (MCCUNE; MERFFORD, 1999).

As comparações entre as médias das variáveis ambientais para os quatro setores do relevo de cada braço foram realizadas por meio de análises de variância pelo teste F com comparações múltiplas via "bootstrap" análogas ao procedimento de Tukey, a $5 \%$ de probabilidade.

\section{RESULTADOS E DISCUSSÃO}

\subsection{Ambiente físico}

Nos três braços da voçoroca (Figura 1), foram identificados solos pertencentes a três classes, a saber: Cambissolos, Gleissolos e Neossolos. Na baixada úmida e terço inferior do braço "A" foi encontrado o Neossolo Flúvico Tb distrófico típico. Nos terços médio e superior $\mathrm{da}$ encosta sul e contíguas às entradas dos braços "B" e "C", ocorre uma transição de Cambissolo Flúvico Tb distrófico típico a sedimentos provenientes da continuidade dos processos erosivos. O Gleissolo Háplico Tb distrófico típico compõe os terços médio e superior da outra encosta do braço "A". Em "B", só foram observados sedimentos, já que os processos erosivos encontram-se bastante ativos, enquanto que em "C" fora apenas diagnosticada a transição de Cambissolo Flúvico Tb distrófico típico a sedimentos. Já na área de confluência dos três braços, o solo predominante foi o Cambissolo Háplico Tb distrófico típico.

O material originado da alteração do gnaissegranítico, precursor das classes de solos predominantes na região de estudo (Latossolos e Cambissolos), é altamente susceptível à erosão (SILVA et al., 1993), além de desenvolver solos de baixa fertilidade (REATTO et al., 2008). De acordo com Silva et al. (1993), as voçorocas não desenvolvidas por atividades antrópicas estão associadas aos Cambissolos que formam sistemas pedológicos muito instáveis devido aos declives acentuados, pequena espessura do sólum, elevados teores de silte e areia fina, vegetação predominante de campo cerrado e baixa permeabilidade. Ainda, segundo os mesmos autores, a concentração de água em algum ponto do terreno é suficiente para dar início ao processo erosivo, que pode evoluir facilmente para a forma de voçoroca.

As médias e desvios padrão das variáveis ambientais nos setores dos três braços da voçoroca encontram-se na Tabela 1, juntamente com os resultados de comparações estatísticas.

Tabela 1 - Variáveis do solo superficial $(0-20 \mathrm{~cm})$ e de resistência à penetração (profundidades de 0-20 $\mathrm{cm}, 20-40 \mathrm{~cm}$ e 40-60 $\mathrm{cm}$ ) nos três braços de uma voçoroca em Itumirim, MG. Os valores são médias \pm desvios padrão das $\mathrm{n}$ amostras de cada um dos quatro setores dos três braços da voçoroca. Em que testes de $\mathrm{F}$ indicaram diferenças significativas entre os quatro setores. As médias seguidas de letras diferentes são significativamente diferentes. Em que: RP = resistência do solo à penetração; $\mathrm{U} \% \mathrm{Max}=$ umidade máxima; $\mathrm{U} \% \mathrm{Min}=$ umidade mínima; $\mathrm{U} \% \mathrm{Amp}$ = amplitude entre umidade máxima e mínima.

Table 1 - Variables of topsoil $(0-20 \mathrm{~cm}$ ) and resistence to penetration (depths of 0-20 cm, 20-40 cm and 40-60 cm) in three arms of a gully in Itumirim, MG. Values are means \pm standard deviations of $n$ samples from each of the four sections of the three arms of the gully. F tests indicated significant differences among the four sections, means followed by different letters are significantly different, where $R P=$ soil resistance to penetration, $U \%$ Max = maximum moisture, $U \%$ Min = minimum moisture, $U \%$ Amp = range between maximum and minimum moisture.

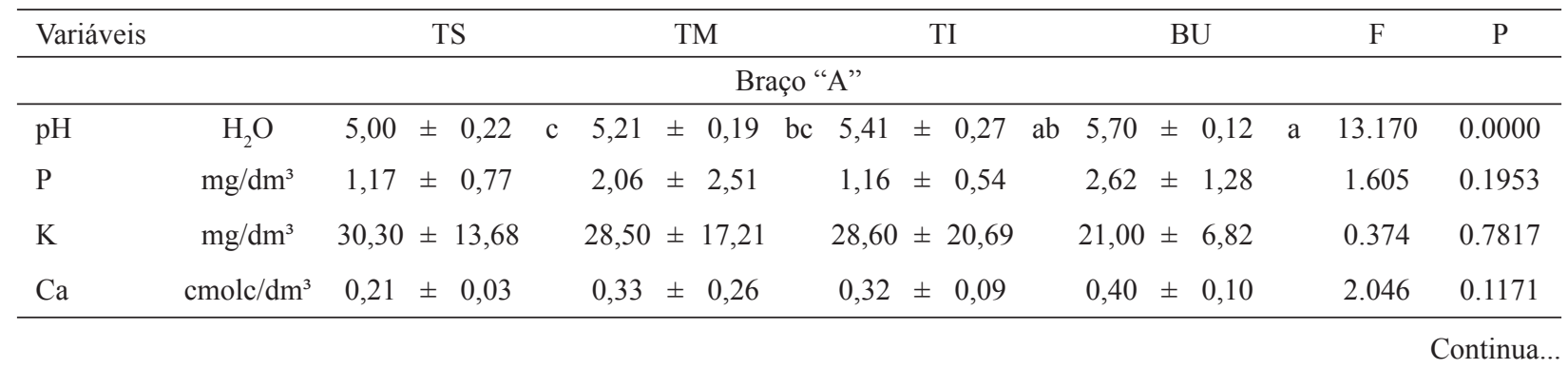

To be continued... 
Tabela 1 - Continua...

Tabela 1 - Continued...

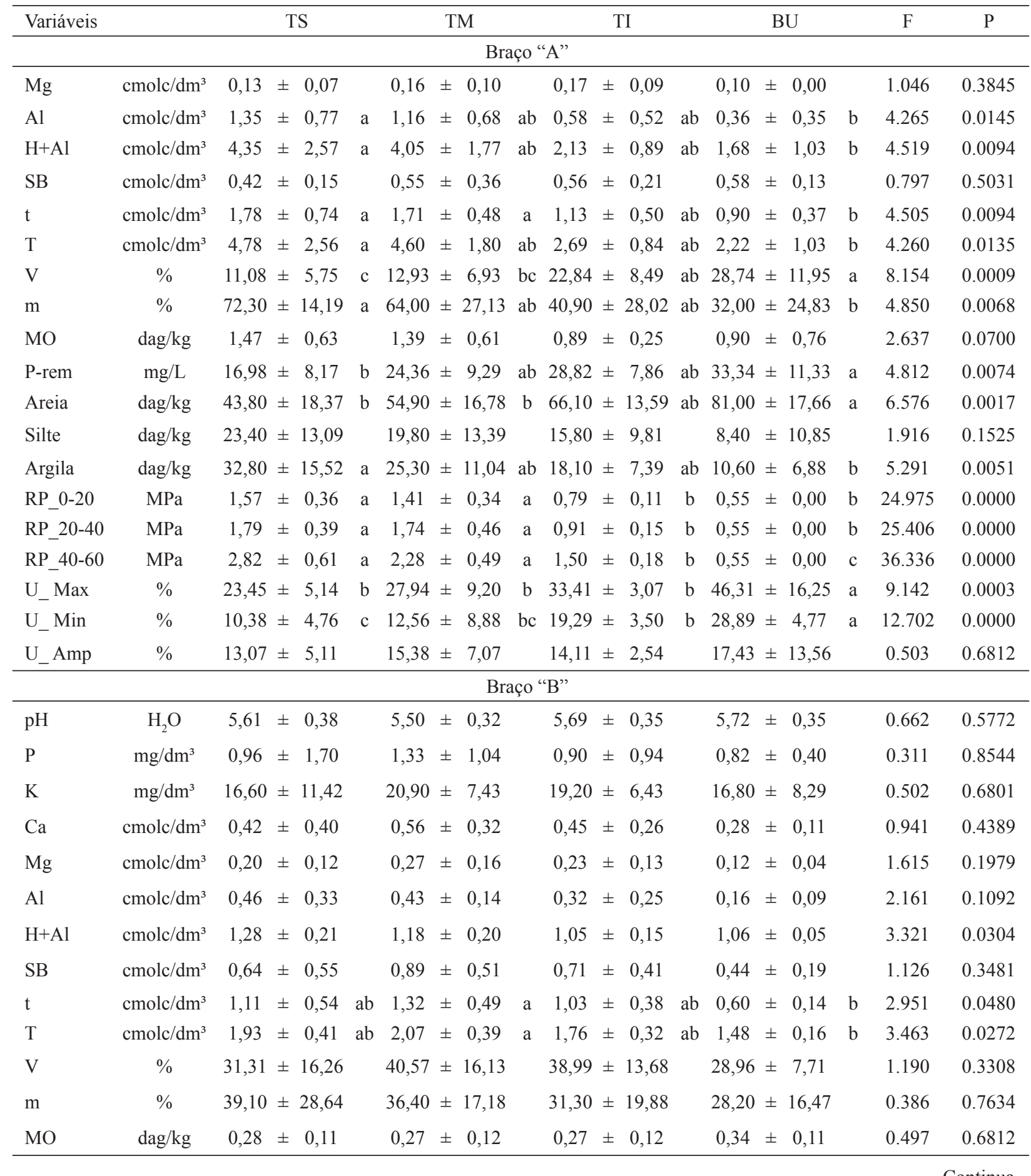


Tabela 1 - Continua...

Tabela 1 - Continued...

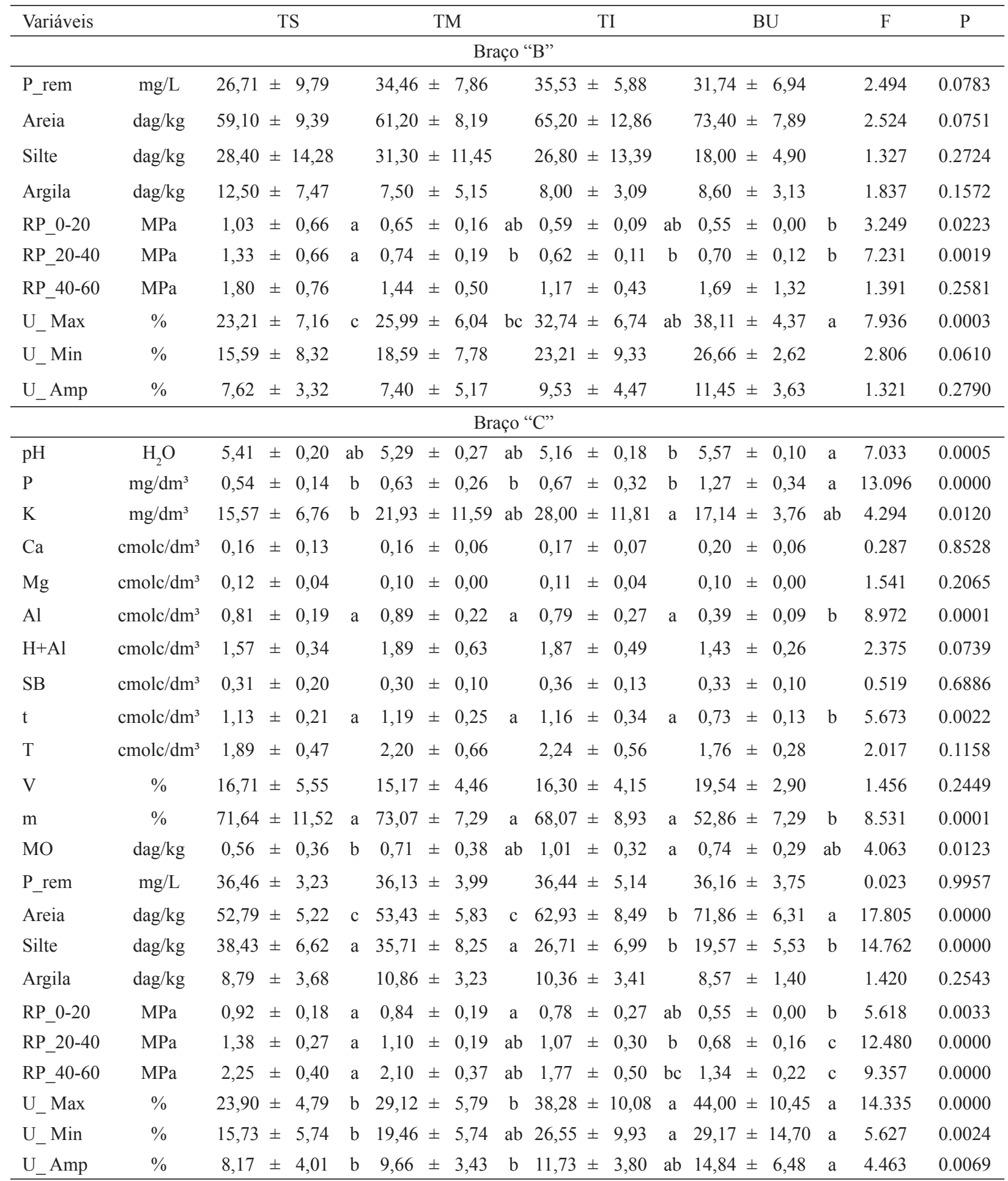

Cerne, Lavras, v. 17, n. 2, p. 161-180, abr./jun. 2011 
As médias de $\mathrm{pH}$ indicaram acidez média (COMISSÃO DE FERTILIDADE DO SOLO DO ESTADO DE MINAS GERAIS - CFSEMG, 1999) em praticamente todos os setores dos três braços, exceto o terço superior de "A", sendo neste caso, o valor médio considerado como acidez elevada. Os maiores valores médios de $\mathrm{pH}$ foram encontrados na baixada úmida dos três braços. Apenas em "A" houve um decréscimo contínuo do valor de $\mathrm{pH}$ à medida que foi aumentado o gradiente topográfico em direção ao terço superior. Já a saturação por $\mathrm{Al}^{3+}(\mathrm{m})$ mostrou padrão oposto, com valores médios menores na baixada úmida. Somente a baixada úmida em "B" apresentou valores médios de saturação por $\mathrm{Al}^{3+}$ considerados como baixo (CFSEMG, 1999), enquanto que os demais setores de " $\mathrm{B}$ ", a baixada úmida e o terço inferior de "A" apresentaram valores considerados médios. Já os terços médio e superior de "A" e todos os setores de "C" apresentaram valores considerados altos. Nos braços "A" e "B", houve um aumento contínuo do valor de saturação por $\mathrm{Al}^{3+}$ à medida que foi aumentando o gradiente topográfico em direção ao terço superior.

Em valores de $\mathrm{pH}$ do solo iguais ou inferiores a 5,0 , podendo ocorrer também em solo com $\mathrm{pH}$ até $5,5, \mathrm{o}$ ín trivalente $\mathrm{Al}^{3+}$, considerado o mais tóxico, prevalece na solução do solo, inibindo o crescimento de raízes (KOCHIAN et al., 2002). De acordo com Fageria (1984), para uma dada espécie, o pH crítico das concentrações tóxicas, depende de vários fatores do solo, como os minerais argilosos predominantes, nível de matéria orgânica e concentrações de outros cations, ânions e sais totais.

A soma de bases (SB), resultado da soma dos níveis de $\mathrm{Ca}, \mathrm{Mg}$ e $\mathrm{K}$, mostra que os valores médios são considerados como muito baixo (CFSEMG, 1999) em todos os setores dos braços " $\mathrm{A}$ " e "C $\mathrm{C}$ ", bem como na baixada úmida de "B". Já nos terços inferior, médio e superior de "B", esses valores são considerados como baixo (CFSEMG, 1999).

Com relação à matéria orgânica, todos os setores de "B" e o terço superior de "C" apresentaram valores médios considerados como muito baixos. Já, nos demais setores de "C" e em todos os setores de "A", esses valores são baixos (CFSEMG, 1999). Pode-se notar que em "A" os maiores valores médios são observados nos terços médio e superior, diferente do que ocorre em "C", em que a baixada úmida e o terço inferior apresentaram os maiores valores. A matéria orgânica pode ser considerada como sinônimo de fertilidade dos solos sob condições tropicais (RAIJ, 1981), além de ter um efeito importante sobre a estruturação do solo e formação de agregados estáveis (RESENDE, 1985), favorecendo uma maior permeabilidade do solo e reduzindo sua suscetibilidade à erosão (BAHIA et al., 1992). A ausência de matéria orgânica em solos degradados faz com que estes apresentem baixa resiliência, ou seja, a reação ambiental para retorno às condições anteriores pode não ocorrer ou ser muito lenta (CARPANEZZI et al., 1990).

De modo geral, há um predomínio de solos com altos teores de areia nos três braços da voçoroca. Observa-se também que, quanto mais próximo da baixada úmida, maior é a quantidade de areia no solo, havendo uma redução gradativa com a aproximação do terço superior. Segundo Goulart (2005), quanto mais próximo do gradiente inferior da voçoroca, menor a quantidade de argila no solo, ocorrendo o inverso para a areia, refletindo em aumento da granulometria do solo, demonstrando que as partículas mais finas são retiradas do sistema à medida que o processo de voçorocamento intensifica-se.

Como a parte mais ativa do solo e de maior importância é a integrada pelas menores partículas e como minerais argilosos e compostos orgânicos, em virtude dos seus tamanhos, áreas específicas e propriedades de superfície, atuam como agentes cimentantes entre partículas grosseiras, como silte e areia (GUÉRIF, 1988; RESENDE et al., 2007), pode-se julgar os efeitos desse evento sobre a erodibilidade e fertilidade do solo. Observa-se, na Tabela 1, que os três braços da voçoroca apresentaram valores médios para a CTC efetiva ( $\mathrm{t}$ ) considerados muito baixos (baixada úmida de "B" e "C") e baixos (demais setores) (CFSEMG, 1999).

Os valores máximos ( $\mathrm{U} \%$ Max) e mínimos ( $\mathrm{U} \%$ Min) de umidade do solo, ou seja, aqueles verificados respectivamente nos períodos mais chuvosos e secos mostram que, em todos os setores dos três braços, os valores são sempre menores à medida que há uma ascensão no gradiente topográfico (GOULART, 2005). O maior e o menor valor de umidade do solo foi registrado respectivamente na baixada úmida e terço superior, ambos do braço "A". Esperava-se que o menor valor de umidade fosse encontrado em "B", já que, nesta área, praticamente não existe vegetação e teoricamente há uma maior evaporação de água do solo (BRAGAGNOLO; MIELNICZUK, 1990). As maiores amplitudes (U\% Amp) de valores para umidade do solo foram todas observadas na baixada úmida dos três braços, evidenciando uma maior instabilidade hídrica nestes setores. 
Os resultados médios relacionados à resistência do solo à penetração indicam que ocorre um maior adensamento do solo de acordo com a topografia no sentido baixada úmida - terço superior, inverso do que foi observado para umidade do solo. Estes resultados concordam com os estudos desenvolvidos por Raney e Edminster (1961), citados por Silva Júnior (2001), nos quais se concluiu que, em qualquer densidade do solo, a resistência mecânica à penetração está inversamente relacionada ao teor de água. Klein et al. (1998) ressaltam, ainda, que pequenas alterações na condição de umidade do solo proporcionam variações acentuadas na resistência do solo à penetração. Porém, nas profundidades de 20-40 e 40-60 cm de "B" os solos da baixada úmida parecem ser mais adensados que os do terço inferior. Tal situação pode ser explicada em função de haver uma maior proximidade com o material de origem do solo nestes locais, onde, em alguns pontos da baixada úmida de "B", ocorreram materiais "pedregosos" dificultando a penetração. Percebe-se também que, quanto maior a profundidade do solo no perfil de $0-60 \mathrm{~cm}$, maior é a resistência à penetração, indicando adensamento do solo. Esses aumentos estão relacionados, possivelmente, com a redução do teor de matéria orgânica nas camadas mais profundas do solo (FIALHO et al., 1991). Verifica-se que, em geral, os valores médios de resistência do solo à penetração foram considerados baixos a moderados, de acordo com a classificação proposta por Soil Survey Staff (1993). Somente o terço superior de "A" e "C" e na profundidade de 40-60 cm tiveram os valores de resistência do solo à penetração (RP) tidos como altos, em que valores de 2,0 MPa são considerados limites entre as classe de resistência à penetração moderada e alta. Segundo Arshad et al. (1996), em solos com resistência à penetração maior que 2,0 $\mathrm{MPa}$, o crescimento de raízes é limitado. Para Miller (1987), a penetração das raízes pode ser reduzida se a resistência do solo atingir valores da ordem de 3,0 $\mathrm{MPa}$. Entretanto, segundo Ehlers et al. (1983), quando o manejo adotado inclui práticas conservacionistas, como manutenção da serapilheira e revolvimento mínimo do solo, os valores críticos são da ordem de 5,0 MPa, já que este aspecto está relacionado à permanência da porosidade e à atividade biológica do solo mais efetiva, propiciando uma maior estabilidade dos agregados.

\subsection{Estrutura do componente regenerante}

Através do levantamento estrutural, foram registradas, para o estrato arbustivo-arbóreo, nos três braços da área de estudo, 28 espécies, pertencentes a 22 gêneros e 13 famílias botânicas (Tabela 2), com destaque especial para as famílias Asteraceae e Melastomataceae.

Verifica-se que as diferentes espécies que fazem parte do grupo das "graminóides" e "samambaias" dominaram amplamente todos os setores dos três braços da voçoroca (Tabela 2). No braço "A" as espécies de "graminóides" apresentaram os maiores valores do índice de cobertura em todos os setores, com exceção do terço médio, em que foram suplantadas pelas "samambaias". Em “B”, apresentou-se baixa colonização por vegetação, porém mais uma vez houve o predomínio das "graminóides". Os maiores valores de índice de cobertura para o braço "B" foram obtidos em todos os setores pelas espécies de "graminóides". Já o braço "C" foi quase que totalmente colonizado pelas espécies do grupo das "samambaias" (Tabela 2), com os valores de índice de cobertura superiores em todos os setores para esse grupo de planta, assim como foi a única área em que todos os setores apresentaram valores médios de saturação por $\mathrm{Al}^{3+}$ (Tabela 1) considerados altos (CFSEMG, 1999).

Com relação à ausência de toques (Tabela 2), os braços " $\mathrm{A}$ " $\mathrm{e}$ "C" foram os que apresentaram os menores valores, ou seja, são áreas que possuem um maior recobrimento do solo. No caso de "A", houve um maior recobrimento do solo nos terços médio e superior, enquanto que, em "C", foram a baixada úmida e o terço inferior que apresentaram um maior recobrimento do solo. Esses resultados coincidem também com o maior teor de matéria orgânica encontrado no solo (Tabela 1).

Observa-se na Tabela 2 que ao sair de um ambiente extremamente encharcado para um com maior oxigenação, as espécies de maior porte já ocorrem com mais frequência (FARIAS et al., 1993). Isso é o que acontece nos terços médio e superior das encostas, com exceção do braço "B", onde só existem elementos arbustivo-arbóreos no terço superior.

\subsection{Análise das relações espécie-ambiente}

Os resultados da análise de correspondência canônica (CCA) estão representados nas Tabelas 3 e 4 e nos diagramas de ordenação das Figuras 3, 4 e 5. Os autovalores da CCA para os dois primeiros eixos de ordenação obtidos para o braço " $A$ " foram de 0,409 (eixo 1) e 0,251 (eixo 2), ambos considerados baixos ( $<0,5$ sensu) (Braak, 1995). O autovalor baixo indica que a maioria das espécies está distribuída ao longo de todo o gradiente.

Cerne, Lavras, v. 17, n. 2, p. 161-180, abr./jun. 2011 


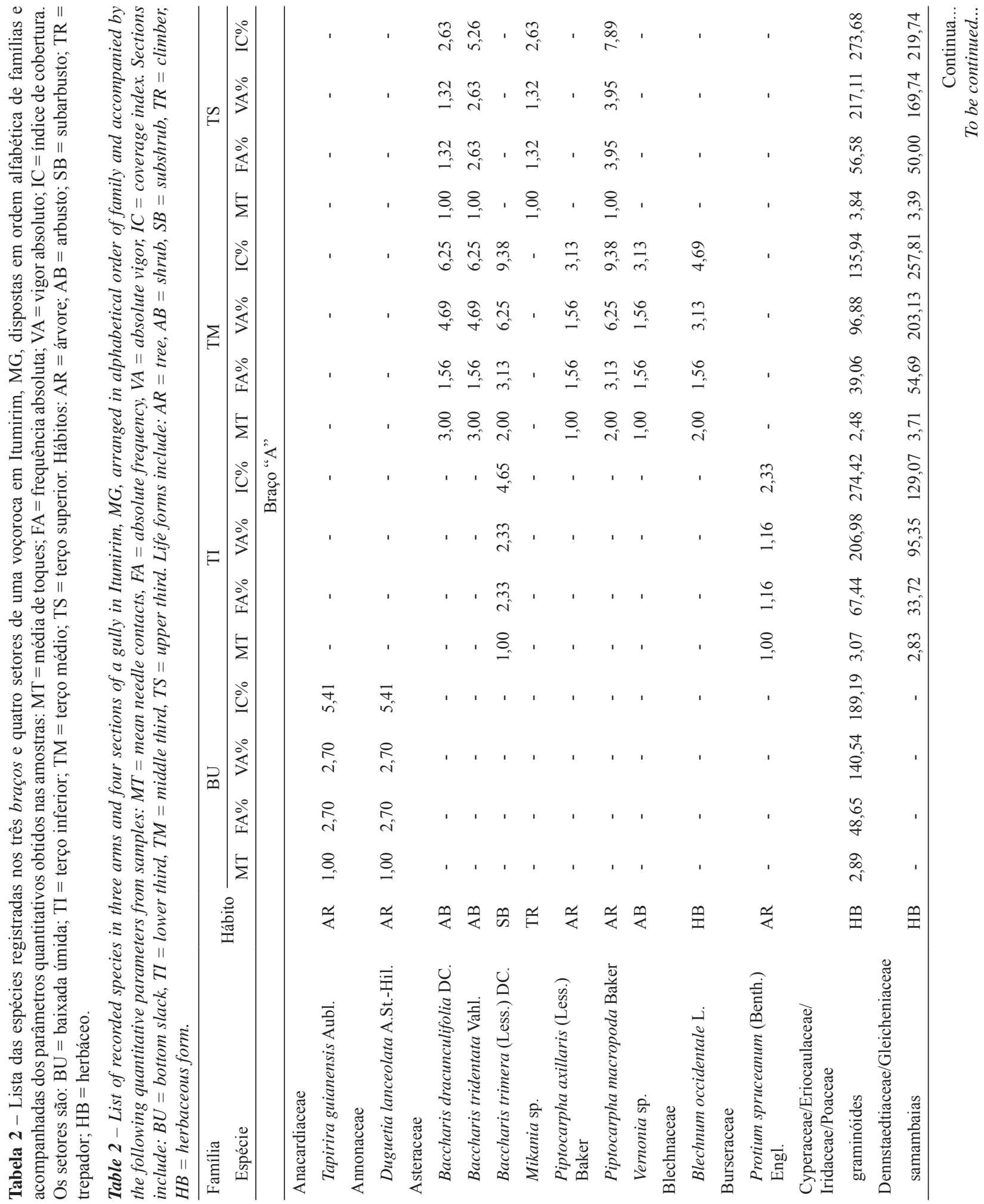


Interações espécie-ambiente na colonização ...

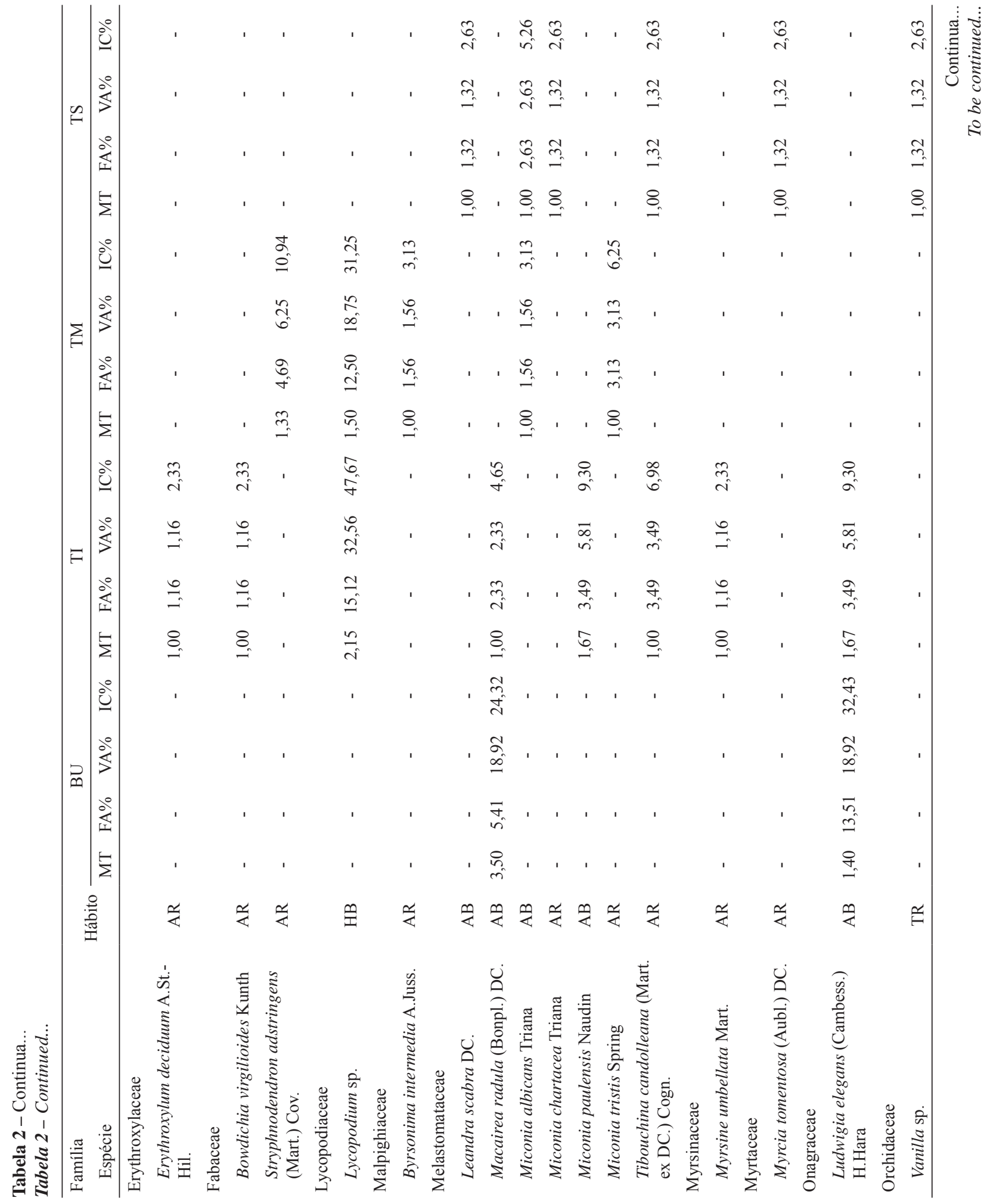




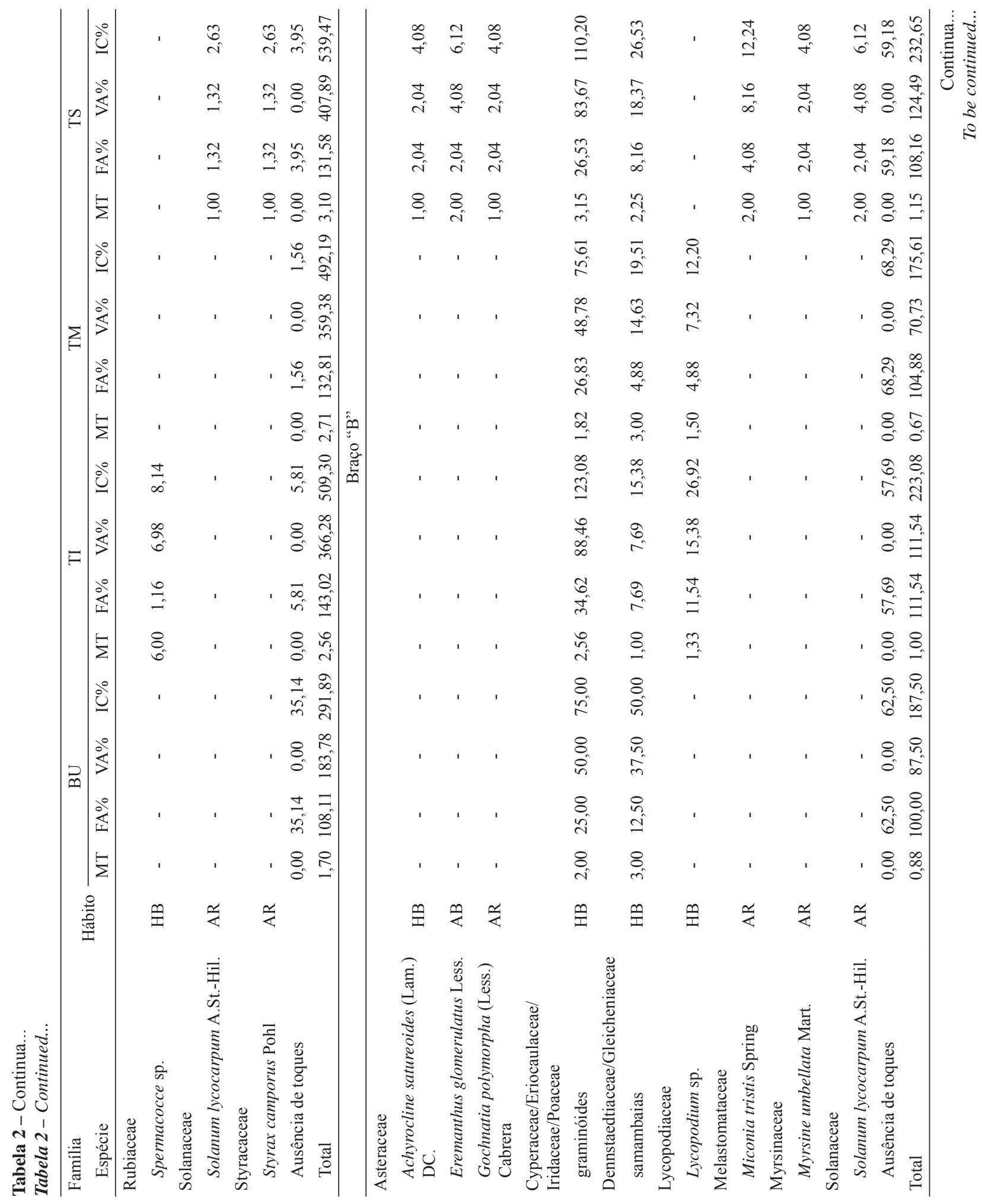

Cerne, Lavras, v. 17, n. 2, p. 161-180, abr./jun. 2011 


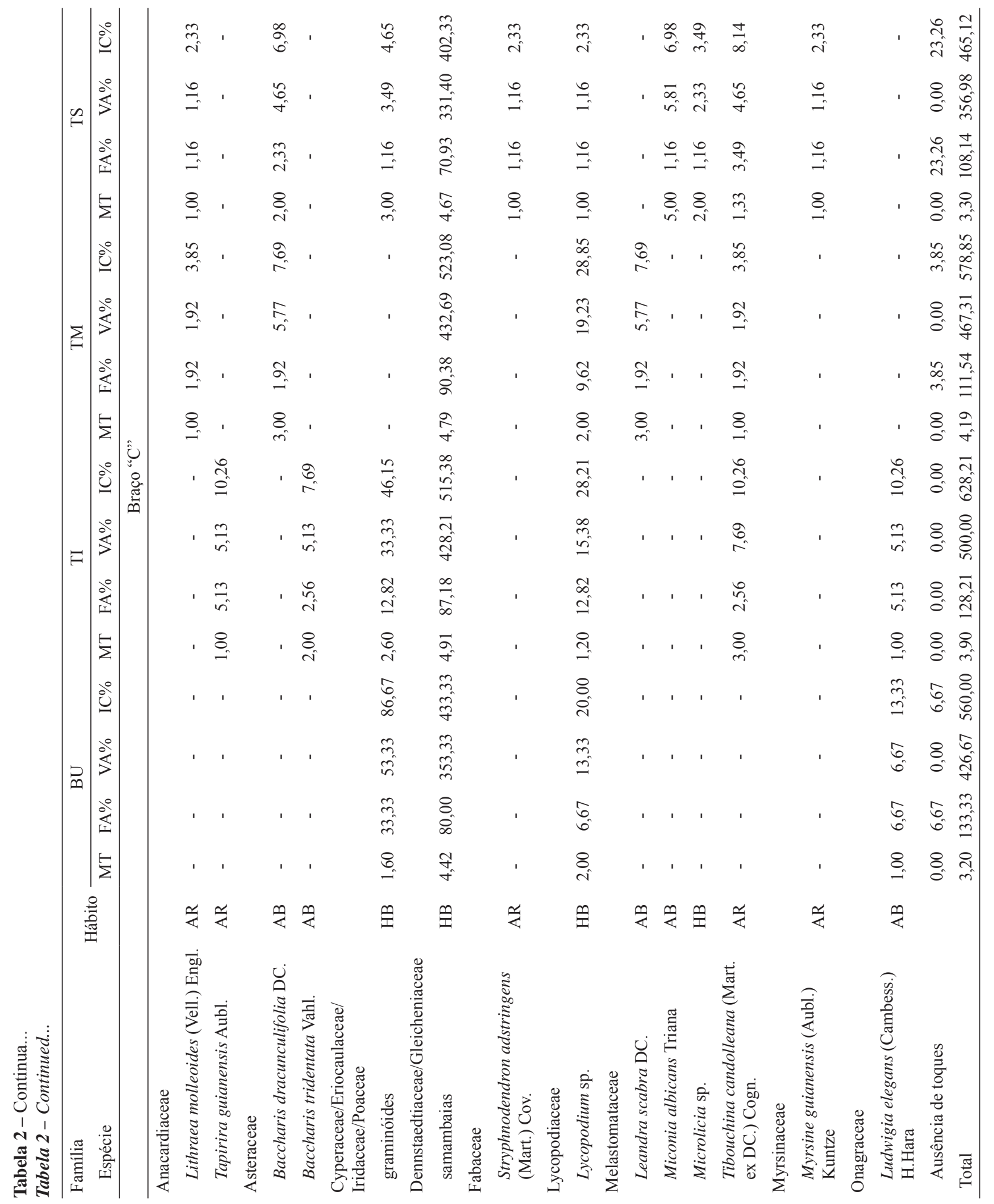


Tabela 3 - Resumo dos resultados da análise de correspondência canônica (CCA) para os braços "A", "B" e "C" de uma voçoroca em Itumirim, MG. São fornecidos resultados para os dois primeiros eixos de ordenação.

Table 3 - Result summary of a canonical correspondence analysis (CCA) for arms 'A', 'B' and 'C' of a gully in Itumirim, MG. Results are provided for the first two ordination axes.

\begin{tabular}{lcccccc}
\hline \multirow{2}{*}{ Resumo CCA } & \multicolumn{2}{c}{ Braço "A" } & \multicolumn{2}{c}{ Braço "B" } & \multicolumn{2}{c}{ Braço "C" } \\
\cline { 2 - 7 } & eixo 1 & eixo 2 & eixo 1 & eixo 2 & eixo 1 & eixo 2 \\
\hline Autovalores & 0,409 & 0,251 & 0,128 & 0,063 & 0,005 & 0,002 \\
Variância dos dadosdas espécies (\%) & 9,6 & 5,9 & 16,3 & 8,0 & 10,5 & 4,1 \\
Variância explicada cumulativa (\%) & 9,6 & 15,5 & 16,3 & 24,3 & 10,5 & 14,6 \\
Correlações espécie-ambiente & 0,927 & 0,934 & 0,714 & 0,631 & 0,560 & 0,570 \\
Significância das correlações pelo & 0,050 & 0,020 & 0,232 & 0,207 & 0,080 & 0,030 \\
teste de Monte Carlo & & & & & & \\
\hline
\end{tabular}

Tabela 4 - Coeficientes de correlação entre as variáveis ambientais e os dois primeiros eixos de ordenação da análise de correspondência canônica (CCA). Dados obtidos nos braços "A", "B" e "C" de uma voçoroca em Itumirim, MG. Onde: $\mathrm{U} \%$ Max = umidade máxima; $\mathrm{U} \%$ Min = umidade mínima; RP1, RP2 e RP3 = resistência do solo à penetração, respectivamente nas profundidades de $0-20 \mathrm{~cm}, 20-40 \mathrm{~cm}$ e $40-60 \mathrm{~cm}$

Table 4 - Coefficients of correlation between environmental variables and the first two ordination axes of the canonical correspondence analysis (CCA). Data obtained in arms ' $A$ ', ' $B$ ' and ' $C$ ' of a gully in Itumirim, MG. U\% Max = maximum moisture; $U \%$ Min = minimum moisture $; R P 1, R P 2$ and $R P 3=$ soil resistance to penetration at depths $0-20 \mathrm{~cm}, 20-40 \mathrm{~cm}$ and $40-60 \mathrm{~cm}$, respectively.

\begin{tabular}{lcccccc}
\hline & \multicolumn{2}{c}{ Braço “A” } & \multicolumn{2}{c}{ Braço "B" } & \multicolumn{2}{c}{ Braço "C" } \\
Variáveis & eixo 1 & eixo 2 & eixo 1 & eixo 2 & eixo 1 & eixo 2 \\
\hline $\mathrm{pH}$ & 0.640 & 0.012 & - & - & - & - \\
$\mathrm{A} 1$ & - & & - & - & - & - \\
$\mathrm{V}$ & 0.514 & 0.110 & - & - & - & - \\
$\mathrm{t}$ & - & - & $-0,374$ & 0,150 & - & - \\
$\mathrm{MO}$ & - & - & 0,608 & $-0,020$ & - & - \\
Areia & - & - & - & - & 0.393 & -0.116 \\
Silte & - & - & $-0,469$ & $-0,065$ & -0.350 & 0.121 \\
Argila & - & - & 0,486 & 0,232 & - & - \\
RP1 & -0.720 & 0.105 & 0.299 & 0,480 & -0.401 & -0.214 \\
RP2 & -0.788 & -0.140 & - & - & -0.324 & -0.355 \\
RP3 & -0.786 & -0.192 & - & - & -0.393 & 0.059 \\
U\% Max & 0.728 & 0.022 & - & - & 0.273 & 0.216 \\
U\% Min & 0.730 & 0.033 & - & - & - & - \\
\hline
\end{tabular}

Os dois primeiros eixos explicaram apenas 9,6\% (eixo 1) e $5,9 \%$ (eixo 2) da variância global dos dados (total acumulado: 15,5\%), indicando muito 'ruído' ou variância remanescente não explicada. No entanto, 'ruído' elevado constitui uma característica comum em dados de vegetação e isto não prejudica a significância das relações espécie-ambiente (BRAAK, 1987). Para o braço “B”, os autovalores para os dois primeiros eixos de ordenação da CCA, foram de 0,128 (eixo 1) e 0,063 (eixo 2), e os dois primeiros eixos explicaram apenas $16,3 \%$ (eixo 1) e $8,0 \%$ (eixo 2) da variância global dos dados (total acumulado: $24,3 \%$ ), indicando novamente muito 'ruído' ou variância remanescente não explicada. Já em "C", os autovalores obtidos para os dois primeiros eixos de ordenação canônica foram 0,005 (eixo 1) e 0,002 (eixo 2), com o primeiro eixo explicando $10,5 \%$ (eixo 1 ) e o segundo $4,1 \%$ (eixo 2 ) da variância global dos dados com um total acumulado de $14,6 \%$, indicando também a presença de muito 'ruído' ou variância remanescente não explicada.

Verificou-se, através da CCA, que as correlações espécie-ambiente nos dois primeiros eixos para o braço "A" foram de 0,927 (eixo 1) e 0,934 (eixo 2), sendo que ambas foram significativas pelo teste de permutação de Monte Carlo ( $\mathrm{p} \leq 0,05)$ (Tabela 3). Enquanto que no braço "B", as correlações espécie-ambiente não foram significativas $(\mathrm{p} \leq 0,05)$. Já para o braço " $\mathrm{C}$ ", as correlações foram de 0,560 (eixo 1) e 0,570 (eixo 2), porém apenas o segundo eixo foi significativo $(\mathrm{p} \leq 0,05)$ de acordo com o referido teste.

À exceção da resistência do solo à penetração nas profundidades $0-20 \mathrm{~cm}$ (RP1) em "B" e 20-40 cm (RP2) em " $C$ ", que apresentou maior correlação com o eixo 2 (Tabela 4), todas as demais variáveis ambientais apresentaram correlação mais forte com o eixo 1 .

Cerne, Lavras, v. 17, n. 2, p. 161-180, abr./jun. 2011 

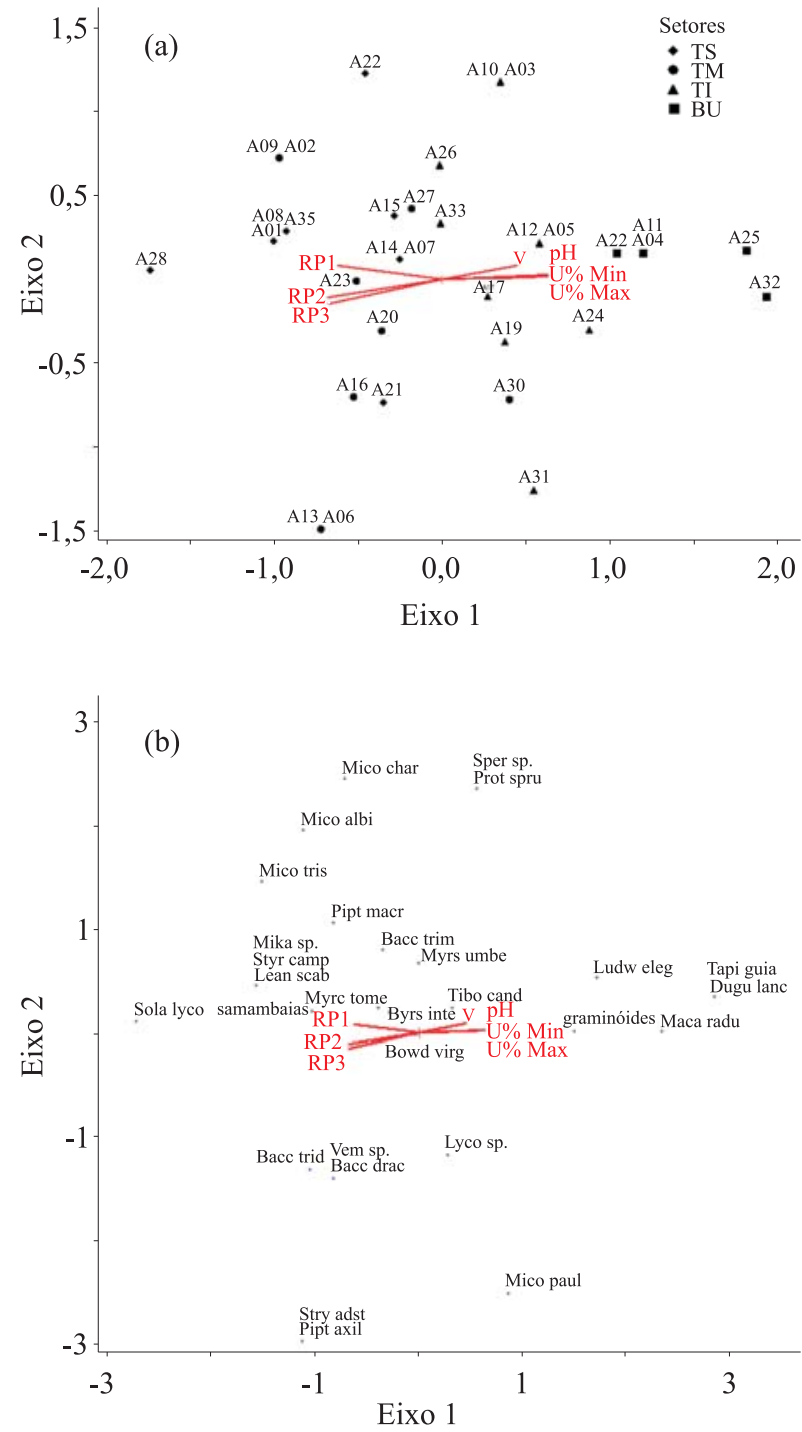

Figura 3 - Análise de correspondência canônica (CCA): diagramas de ordenação dos setores (a) e espécies (b) baseados na distribuição das abundâncias de 29 espécies em 35 setores do braço "A" de uma voçoroca em Itumirim, MG, e sua correlação com as sete variáveis ambientais utilizadas (vetores). As espécies são identificadas pelo seu nome abreviado. em que: $\mathrm{BU}=$ baixada úmida; $\mathrm{TI}=$ terço inferior; $\mathrm{TM}=$ terço médio; $\mathrm{TS}=$ terço superior.

Figure 3 - Canonical correspondence analysis (CCA): ordination diagrams of sections (a) and species (b) based on the abundance distribution of 29 species across 35 sections of arm ' $A$ ' of a gully in Itumirim, $M G$, and relevant correlation with the seven environmental variables used (drivers). Species are identified by their abbreviated name. $B U=$ bottom slack, $T I$ = lower third, TM = middle third, TS = upper third.
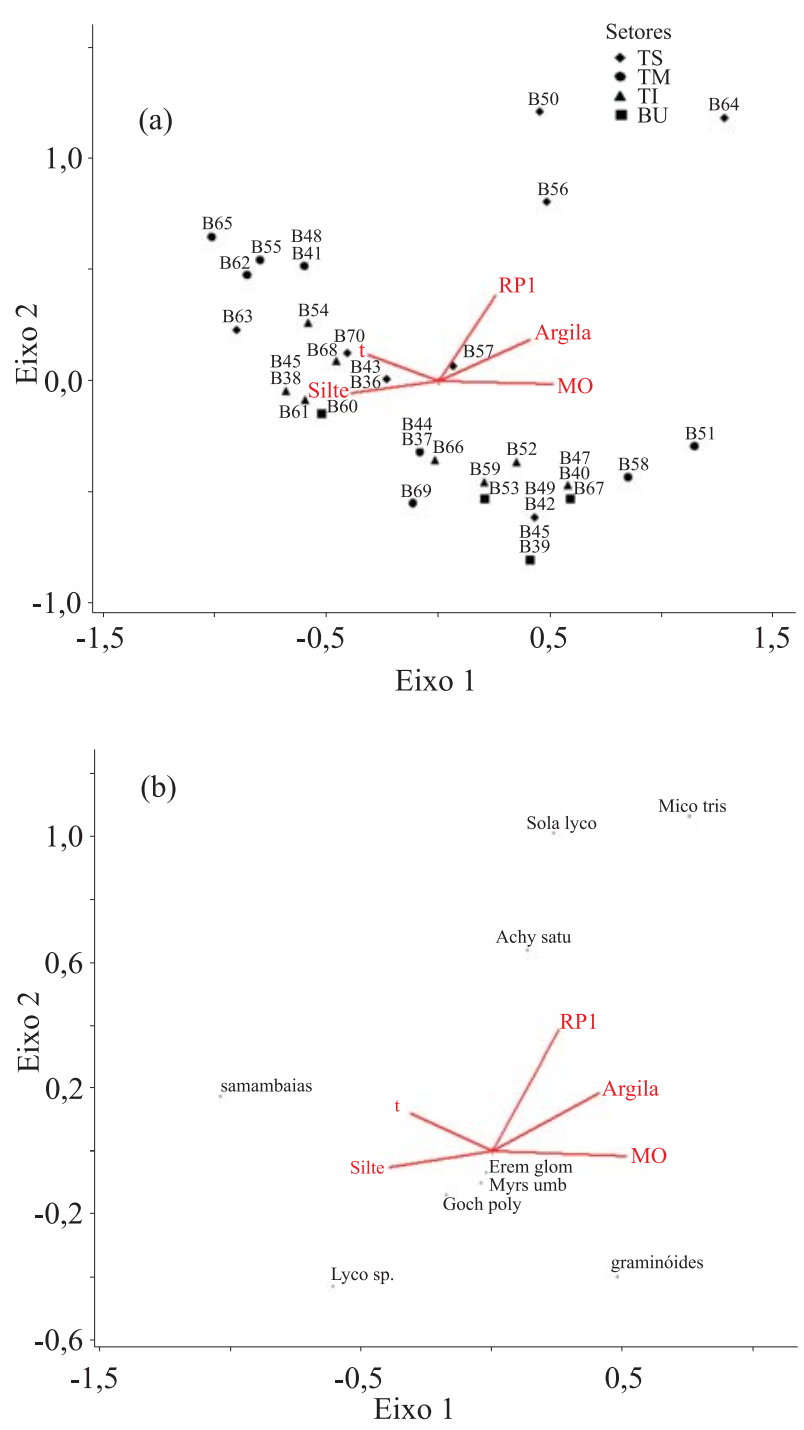

Figura 4 - Análise de correspondência canônica (CCA): diagramas de ordenação dos setores (a) e espécies (b) baseados na distribuição das abundâncias de 10 espécies em 35 setores do braço "B" de uma voçoroca em Itumirim, MG, e sua correlação com as quatro variáveis ambientais utilizadas (vetores). As espécies são identificadas pelo seu nome abreviado. Em que: $\mathrm{BU}=$ baixada úmida; $\mathrm{TI}=$ terço inferior; $\mathrm{TM}=$ terço médio; $\mathrm{TS}=$ terço superior.

Figure 4 - Canonical correspondence analysis (CCA): ordination diagrams of sections (a) and species (b) based on the abundance distribution of 10 species across 35 sections of arm ' $B$ ' of a gully in Itumirim, $M G$, and relevant correlation with the four environmental variables used (drivers). Species are identified by their abbreviated name. $B U=$ bottom slack, $T I$ $=$ lower third, $T M=$ middle third, $T S=$ upper third.

Cerne, Lavras, v. 17, n. 2, p. 161-180, abr./jun. 2011 

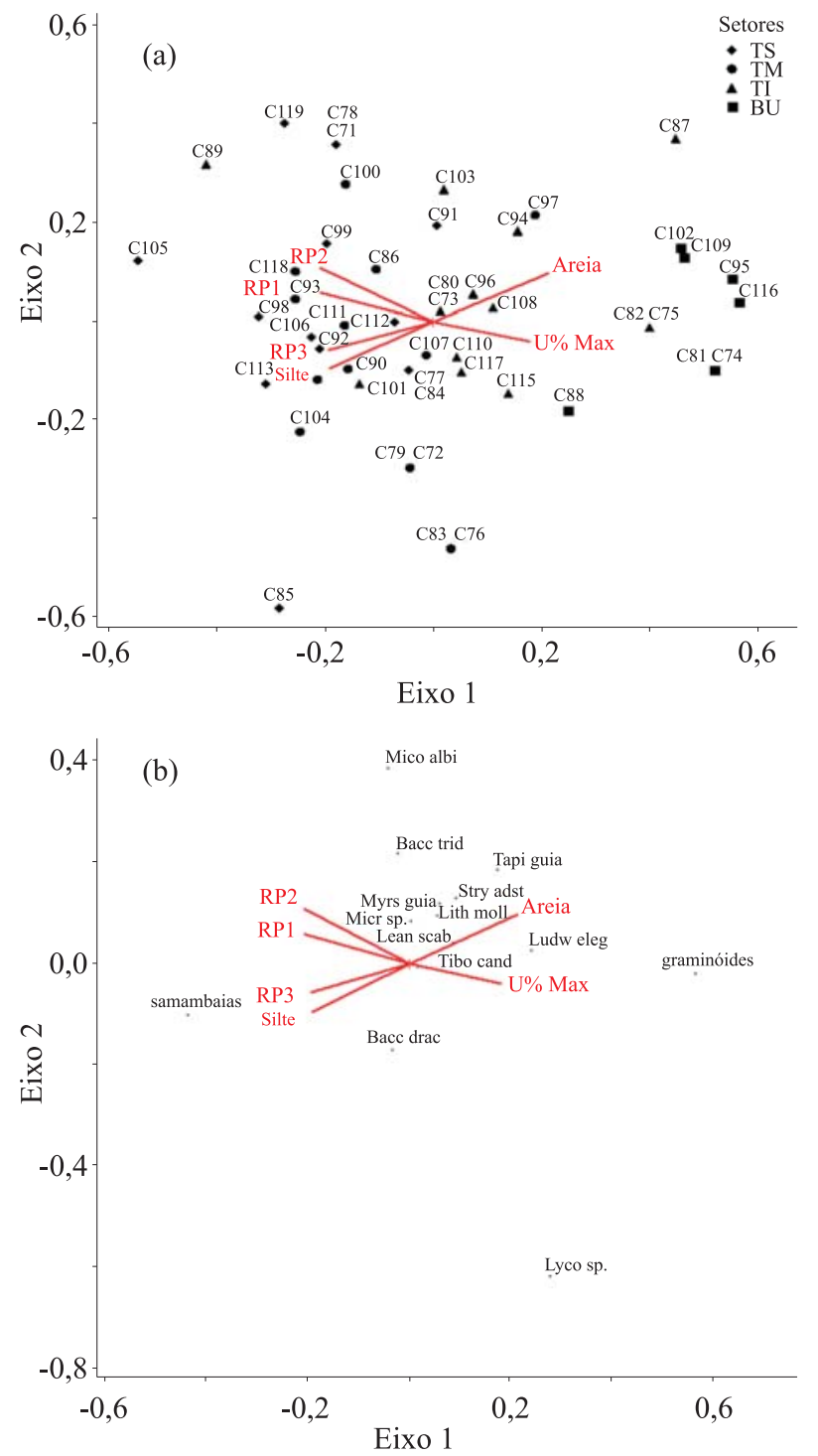

Figura 5 - Análise de correspondência canônica (CCA): diagramas de ordenação dos setores (A) e espécies (B) baseados na distribuição das abundâncias de 14 espécies em 49 setores do braço " $\mathrm{C}$ " de uma voçoroca em Itumirim, $\mathrm{MG}$, e sua correlação com as seis variáveis ambientais utilizadas (vetores). As espécies são identificadas pelo seu nome abreviado. Em que: $\mathrm{BU}=$ baixada úmida; $\mathrm{TI}=$ terço inferior; $\mathrm{TM}=$ terço médio; $\mathrm{TS}=$ terço superior.

Figure 5 - Canonical correspondence analysis (CCA): ordination diagrams of sections (A) and species (B) based on the abundance distribution of 14 species across 49 sections of arm ' $C$ ' of a gully in Itumirim, $M G$, and relevant correlation with the six environmental variables used (drivers). Species are identified by their abbreviated name. $B U=$ bottom slack, $T I=$ lower third, $T M=$ middle third, $T S=$ upper third.

Cerne, Lavras, v. 17, n. 2, p. 161-180, abr./jun. 2011
Para o braço "A", a ordenação dos setores no primeiro eixo (Figura 3A) sugere claramente a existência de um forte gradiente topográfico da baixada úmida para os terços inferior, médio e superior, sendo os dois últimos muito similares entre si. Para os setores "BU" e "TI", as variáveis edáficas que tiveram maior importância foram as seguintes: $\mathrm{pH}$, umidade máxima ( $\mathrm{U} \% \mathrm{Max})$ e umidade mínima (U\% Min) e saturação por bases (V). De acordo com Furtini Neto et al. (2001) e Guilherme et al. (1993), a inundação do solo promove consumo de íons de $\mathrm{H}^{+}$, havendo, com isso, a elevação do $\mathrm{pH}$ do solo, com consequente precipitação de $\mathrm{Al}^{3+}$. Além disso, a presença de Neossolo Flúvico pode justificar a correlação da saturação por bases com os setores "BU" e "TI", já que esta classe de solo é relativamente mais fértil (CARVALHO et al., 2005; RESENDE et al., 2007). Já para os setores "TM" e "TS", a resistência do solo à penetração nas profundidades 0-20 cm (RP1), 20-40 cm (RP2) e 40-60 cm (RP3) foram as variáveis ambientais que tiveram maior relevância. Verifica-se, através da ordenação das espécies pela CCA (Figura 3B), que as espécies Ludwigia elegans, Macairea radula, Duguetia lanceolata, Tapirira guianensis e o grupo das "graminóides" foram correlacionadas com o $\mathrm{pH}$ e, principalmente, com a drenagem mais deficiente do solo. Já as espécies do grupo das "samambaias" apresentaram uma maior correlação com a resistência do solo à penetração na profundidade de 0-20 cm (RP1). Observa-se também que boa parte da distribuição das espécies mostrou-se sem correlação com as principais variáveis ambientais utilizadas na CCA.

Para o braço "B", percebe-se através da ordenação dos setores (Figura 4A) que não houve um padrão de agrupamento entre eles, assim como a falta de correlações claras com as cinco variáveis ambientais de maior peso, exceto a resistência do solo à penetração na profundidade de $0-20 \mathrm{~cm}$ (RP1) que apresentou correlação com algumas áreas do terço superior. Essa falta de padrão no agrupamento entre os setores pode ser justificada pelo fato de que toda a extensão deste braço é composta apenas por sedimentos provenientes de processos erosivos ativos, com total ausência de solo. A ordenação das espécies pela CCA (Figura 4B) mostra, através do primeiro eixo, que as espécies do grupo das "samambaias" apresentaram uma maior correlação com a fração silte e CTC efetiva (t). Já as espécies Achyrocline satureoides, Miconia tristis e Solanum lycocarpum apresentaram correlação no segundo eixo com a resistência do solo à penetração na profundidade $0-20 \mathrm{~cm}$ (RP1). 
Para o braço "C", assim como para o "A", a ordenação dos setores no primeiro eixo (Figura 5A) sugere claramente a existência de um forte gradiente topográfico da baixada úmida para os terços inferior, médio e superior, sendo que novamente os terços médio e superior são muito similares entre si. A fração areia e a umidade no período mais chuvoso (U\% Max) foram as variáveis ambientais que apresentaram a maior correlação com a baixada úmida. Já os terços médio e superior tiveram maior correlação com a fração silte e resistência do solo à penetração nas profundidades de 0-20 cm (RP1), 20-40 cm (RP2) e 40$60 \mathrm{~cm}$ (RP3). Nota-se que a ordenação das espécies pela CCA (Figura 5B) apresenta-se semelhante à "A", onde as espécies Tapirira guianensis, Ludwigia elegans e o grupo das "graminóides" obtiveram uma maior correlação com a fração areia e umidade máxima (U\% Max), que são variáveis ambientais associadas às áreas mais baixas e úmidas. Já o grupo das "samambaias" correlacionou-se com a fração silte e novamente com a resistência do solo à penetração nas profundidades de 0-20 cm (RP1), 20 $40 \mathrm{~cm}$ (RP2) e 40-60 cm (RP3). Segundo Resende et al. (2007), teores elevados de silte fazem com que os solos fiquem mais propensos ao encrostamento na superfície, provocado pelo impacto direto das gotas de chuva, dificultando a germinação e o estabelecimento da plântula. Consequentemente, essa condição ambiental favorece às espécies que apresentam uma maior plasticidade. As demais espécies não apresentaram correlação com as principais variáveis ambientais utilizadas na CCA.

De maneira geral, a ordenação das espécies pela CCA na voçoroca mostra que as espécies do grupo das "graminóides" tendem a ser mais abundantes nas áreas mais baixas, úmidas e relativamente mais férteis, ocorrendo o contrário para as espécies do grupo das "samambaias", já que estas se tornam mais abundantes à medida que há uma ascensão topográfica com a conseqüente redução da umidade e aumento do adensamento do solo. Segundo Ashton (1990), é comum que a dominância ecológica seja mais pronunciada nos extremos de alta e baixa disponibilidade de recursos do solo. A ordenação das espécies também mostrou que a grande maioria das espécies de hábito arbustivo-arbóreo não apresentou importantes correlações com as principais variáveis ambientais utilizadas na CCA, talvez influenciadas pela baixa abundância das mesmas na regeneração natural. Outra característica importante da voçoroca estudada foi a presença de um grande número de espécies raras, o que é, na verdade, outro aspecto da forte dominância ecológica (CARVALHO et al., 2005).
A baixa disponibilidade de nutrientes no solo conduz à persistência de espécies de pouca demanda nutricional, restringindo o estabelecimento e crescimento de indivíduos arbustivos e arbóreos, normalmente dependentes de maior fertilidade (VIEIRA; PESSOA, 2001). Alguns fatores podem interferir na regeneração natural, e consequentemente no sucesso da reabilitação de uma área, como a acidez do substrato (SIQUEIRA, 2002), baixa fertilidade (PARROTTA, 1993; VIEIRA et al., 2001), competição com gramíneas e samambaias agressivas (FARIAS et al., 1993; NEPSTAD et al., 1991), predação de sementes e plântulas (MOUTINHO, 1998), stress hídrico, temperaturas extremas e compactação do substrato (REINERT, 1998; SUN et al., 1995; UHL et al., 1988) e, por fim, os propágulos introduzidos na área proveniente da vegetação vizinha (CAMPELLO, 1998; JESUS; ROLIM, 2005).

\section{AGRADECIMENTOS}

Os autores agradecem à Fundação de Amparo à Pesquisa do Estado de Minas Gerais (FAPEMIG), pelo financiamento ao Projeto (CRA - APQ-3604-5.03/07), à Coordenação de Aperfeiçoamento de Pessoal de Nível Superior (CAPES) pela concessão de bolsa de estudos ao primeiro autor e ao Sr. Sílvio Donizete Rezende, por autorizar a realização deste estudo em sua propriedade.

\section{REFERÊNCIAS}

ALMEIDA, A. L.; ARAÚJO, D. S. D. Comunidades vegetais do cordão arenoso externo da Reserva Ecológica Estadual de Jacarepiá, Saquarema, RJ. Oecologia Brasiliensis, Rio de Janeiro, v. 3, n. 1, p. 47-63, 1997.

ANGIOSPERM PHYLOGENY GROUP. An update of the Angiosperm Phylogeny Group classification for the orders and families of flowering plants: APG II. Botanical Journal of the Linnean Society, London, v. 141, n. 4, p. 399-436, Apr. 2003.

ANTUNES, F. Z. Caracterização climática do Estado de Minas Gerais. Informe Agropecuário, Belo Horizonte, v. 12, n. 138, p. 9-13, jun. 1986.

ARAÚJO, F. S.; MARTINS, S. V.; MEIRA NETO, J. A. A.; LANI, J. L.; PIRES, I. E. Estrutura da vegetação arbustivoarbórea colonizadora de uma área degradada por mineração de caulim, Brás Pires, MG. Revista Árvore, Viçosa, v. 30, n. 1, p. 107-116, jan./fev. 2006.

Cerne, Lavras, v. 17, n. 2, p. 161-180, abr./jun. 2011 
ARAÚJO, G. H. S.; ALMEIDA, J. R.; GUERRA, A. J. T. Gestão ambiental de áreas degradadas. Rio de Janeiro: Bertrand Brasil, 2005. 320 p.

ARSHAD, M. A.; LOWERY, B.; GROSSMAN, B. Physical tests for monitoring soil quality. In: DORAN, J. W.; JONES, A. J. Methods for assessing soil quality. Madison: Soil Science Society of America, 1996. p. 123-141. (SSAA special publication, 49).

ASHTON, P. S. Species richness in tropical forests. In: HOLM-NIELSEN, L. B.; NIELSEN, I. C.; BALSLEV, H. (Eds.). Tropical forests: botanical dynamics, speciation and diversity. London: Academic, 1990. p. 239-251.

BAHIA, V. G.; CURI, N.; CARMO, D. N.; MARQUES, J. J. G. S. M. Fundamentos de erosão do solo: tipos, formas, mecanismos, fatores determinantes e controle. Informe Agropecuário, Belo Horizonte, v. 16, n. 176, p. 25-31, 1992.

BRAAK, C. J. F. The analysis of vegetation environment relationship by canonical correspondence analysis. Vegetatio, Dordrecht, v. 69, n. 1/3, p. 69-77, Apr. 1987.

BRAAK, C. J. F. Ordination. In: JONGMAN, R. H. G.; BRAAK, C. J. F.; TONGEREN, O. F. R. van (Eds.). Data analysis in community and landscape ecology. Cambrigde: Cambrigde University, 1995. p. 91-173.

BRAGAGNOLO, N.; MIELNICZUK, J. Cobertura do solo por palha de trigo e seu relacionamento com a temperatura e umidade do solo. Revista Brasileira de Ciência do Solo, Campinas, v. 14, n. 1, p. 369-374, jun. 1990.

BRASIL. Ministério da Agricultura. Departamento Nacional de Metereologia. Normas climatológicas: 1961-1990. Brasília, 1992. 132 p.

BUSELATO, T. C.; BUENO, O. L. Composição florística de dois campos localizados no município de Montenegro, Rio Grande do Sul, Brasil. Iheringia Série Botânica, Porto Alegre, v. 26, p. 65-84, 1981.

CAMPELLO, E. F. C. Sucessão vegetal na recuperação de áreas degradadas. In: DIAS, L. E.; MELLO, J. W. V. (Eds.). Recuperação de áreas degradadas. Viçosa, MG: UFV, 1998. p. 183-196.

Cerne, Lavras, v. 17, n. 2, p. 161-180, abr./jun. 2011
CARPANEZZI, A. A.; COSTA, L. G. S.; KAGEYAMA, P. Y.; CASTRO, C. F. A. Espécies pioneiras para recuperação de áreas degradadas: observações de laboratórios naturais. In: CONGRESSO FLORESTAL BRASILEIRO, 6., 1990, Campos do Jordão. Anais... Campos do Jordão: SBS, 1990. p. 216-221.

CARVALHO, D. A. Flora fanerogâmica de campos rupestres da Serra da Bocaina, Minas Gerais: caracterização e lista de espécies. Ciência e Prática, Lavras, v. 16, n. 1, p. 97-122, jan./jun. 1992.

CARVALHO, D. A.; OLIVEIRA FILHO, A. T.; VILELA, E. A.; CURI, N.; BERG, E. van den; FONTES, M. A.; BOTEZELLI, L. Distribuição de espécies arbóreo-arbustivas ao longo de um gradiente de solos e topografia em um trecho de floresta ripária do Rio São Francisco em Três Marias, MG, Brasil. Revista Brasileira de Botânica, São Paulo, v. 28, n. 2, p. 329-345, jun. 2005.

CASTELLANI, T. T.; STUBBLEBINE, W. H. Sucessão secundária inicial em mata mesófila, após perturbação por fogo. Revista Brasileira de Botânica, São Paulo, v. 16, n. 2 , p. 181-203, fev. 1993.

COMISSÃO DE FERTILIDADE DO SOLO DO ESTADO DE MINAS GERAIS. Recomendações para o uso de corretivos e fertilizantes em Minas Gerais: $5^{\text {a }}$ aproximação. Viçosa, MG, 1999. 359 p.

EHLERS, W.; KOPKE, V.; HESSE, F.; BOHM, W. Penetration resistance and root growth of oats in tilled and untilled loess soil. Soil Tillage Research, Amsterdam, v. 3, n. 3, p. 261-275, 1983.

EMPRESA BRASILEIRA DE PESQUISA

AGROPECUÁRIA. Manual de métodos de análises de solo. 2. ed. Rio de Janeiro, 1997. 412 p.

\section{EMPRESA BRASILEIRA DE PESQUISA}

AGROPECUÁRIA. Sistema brasileiro de classificação dos solos. 2. ed. Rio de Janeiro, 2006. 306 p.

FAGERIA, N. K. Resposta de cultivares de arroz à aplicação de calcário em solo de cerrado. Pesquisa Agropecuária Brasileira, Brasília, v. 19, n. 7, p. 883-889, jul. 1984.

FARIAS, C. A.; RESENDE, M.; BARROS, N. F.; SILVA, A. F. Dinâmica da revegetação natural de voçorocas na região de Cachoeira do Campo, município de Ouro Preto-MG. Revista Árvore, Viçosa, v. 17, n. 3, p. 314-326, maio/jun. 1993. 
FIALHO, J. F.; BORGES, A. C.; BARROS, N. F. Cobertura vegetal e as características químicas e físicas e atividade da microbiota de um latossolo vermelho-amarelo distrófico. Revista Brasileira de Ciência do Solo, Campinas, v. 15, n. 1, p. 21-28, jun. 1991.

FRIZZO, T. C. E.; PORTO, M. L. Zoneamento da vegetação e sua relação com a ocorrência de estruturas mineralizadas na mina Volta Grande, Lavras do Sul, RS, Brasil. Iheringia Série Botânica, Porto Alegre, v. 59, n. 1, p. 5-12, mar. 2004.

FURTINI NETO, A. E.; VALE, F. R.; RESENDE, A. V.; GUILHERME, L. R. G.; GUEDES, G. A. A. Fertilidade do solo. Lavras: UFLA/FAEPE, 2001. 252 p.

GARDNER, W. H. Water content. In: KLUTE, A. (Ed.). Methods of soil analysis: part I. Madison: Winconsin, 1986. chap. 21, p. 493-544. (Agronomy monograph, 9).

GOODALL, D. W. Some considerations in the use of point quadrats for the analysis of vegetation. Australian Journal of Scientific Research, Melbourne, v. 5, n. 1, p. 1-41, 1952.

GOULART, R. M. Atributos de solos e comportamento de espécies florestais em processo de estabilização de voçorocas. 2005. 91 p. Dissertação (Mestrado em Engenharia Florestal) - Universidade Federal de Lavras, Lavras, 2005.

GUÉRIF, J. Résistance em traction dês agrégats terrux: influence de la texture, de la matiére organique et de la teneur em eau. Agronomie, Paris, v. 8, n. 4, p. 379-386, 1988.

GUILHERME, L. R. G.; CURI, N.; GUEDES, G. A. A.; VALE, F. R. Alterações em $\mathrm{pH}$ ocasionadas por calagem e inundação em solos de várzea cultivados com arroz. Revista Brasileira de Ciência do Solo, Campinas, v. 17, n. 2, p. 149156, dez. 1993.

JESUS, R. M.; ROLIM, S. G. Experiências relevantes na restauração da mata atlântica. In: GALVÃO, A. P. M.; PORFÍRIO-DA-SILVA, V. (Eds.). Restauração florestal: fundamentos e estudos de caso. Colombo: Embrapa Florestas, 2005. p. 59-86.

KLEIN, V. A.; LIBARDI, P. L.; SILVA, A. P. Resistência do solo à penetração sob diferentes condições de umidade. In: CONGRESSO BRASILEIRO DE ENGENHARIA AGRÍCOLA, 3., 1998, Poços de Caldas. Anais... Poços de Caldas: SBEA, 1998. p. 61-63.
KOCHIAN, L. V.; PENCE, N. S.; LETHAM, L. D.; PINEROS, M. A.; MAGALHÃES, J. V.; HOEKENGA, O. A.; GARVIN, D. F. Mechanisms of metal resistance in plants: aluminum and heavy metals. Plant Soil, The Hague, v. 247, p. 109-119, 2002.

MANTOVANI, W. Análise florística e fitossociológica do estrato herbáceo-subarbustivo do cerrado na Reserva Biológica de Mogi-Guaçu e Itirapina, SP. Campinas: Unicamp, 1987. 203 p.

\section{MATTEUCCI, S. D.; COLMA, A. Metodologia para el} estudio de la vegetacion. Washington: Secretaria General de la Organización de los Estados Americanos, 1982. 169 p.

\section{MCCUNE, B.; MEFFORD, M. J. PC-ORD version 4.14:} multivariate analysis of ecological data. Glenden Beach: MjM, 1999. Software. CD-ROM.

MILLER, D. E. Effect of subsoiling and irrigation regime on dry bean production in the Pacific Northwest. Soil Science Society os America Journal, Madison, v. 51, p. 784-787, 1987.

MOUTINHO, P. R. S. Impactos da formação de pastagem sobre fauna de formigas: conseqüência para a recuperação florestal na Amazônia oriental. In: GASCON, C.;

MOUTINHO, P. (Eds.). Floresta Amazônica: dinâmica, regeneração e manejo. Manaus: UFAM, 1998. p. 155-170.

NEPSTAD, D.; UHL, C.; SERRÃO, E. A. Recuperation of a degraded Amazonian landscape: forest recovery and agricultural restoration. Ambio, Oslo, v. 20, n. 6, p. 248-255, 1991.

PARROTTA, J. A. Secondary forest regeneration on degraded tropical lands: the role of plantations as "foster ecosystems". In: LIETH, H.; LOHMANN, M. (Eds.). Restoration of tropical forest ecosystems. Netherlands: Kluwer Academic, 1993. p. 63-73.

PARZANEZE, G. A. C. Gênese e desenvolvimento de voçorocas em solos originados de rochas granitóides na região de Cachoeira do Campo, Minas Gerais. 1991. 117 p. Dissertação (Mestrado em Solos e Nutrição de Plantas) Universidade Federal de Viçosa, Viçosa, 1991.

PEDRO, F. G.; LORANDI, R. Potencial natural de erosão na área periurbana de São Carlos, SP. Revista Brasileira de Cartografia, Rio de Janeiro, v. 56, n. 1, p. 28-33, jan./fev. 2004.

Cerne, Lavras, v. 17, n. 2, p. 161-180, abr./jun. 2011 
QUEIROZ, R.; SOUZA, A. G.; SANTANA, P.; ANTUNES, F. Z.; FONTES, M. Zoneamento agroclimático do Estado de Minas Gerais. Belo Horizonte: Epamig, 1980. 114 p.

RAIJ, B. van. Mecanismos de interação entre solos e nutrientes. In: . Avaliação da fertilidade do solo.

Piracicaba: Instituto da Potassa e Fosfato, 1981. p. 17-31.

REATTO, A.; CORREIA, J. R.; SPERA, S. T.; MARTINS, E. S. Solos do bioma cerrado: aspectos pedológicos. In: SANO, S. M.; ALMEIDA, S. P.; RIBEIRO, J. F. (Eds.). Cerrado: ecologia e flora. Brasília: Embrapa Informações Tecnológicas, 2008. p. 107-149.

REINERT, D. J. Recuperação de solos em sistemas agropastoris. In: DIAS, L. E.; MELLO, J. W. V. (Eds.). Recuperação de áreas degradadas. Viçosa, MG: UFV, 1998. p. 163-176.

RESENDE, M. N. Aplicações de conhecimentos pedológicos à conservação de solos. Informe Agropecuário, Belo Horizonte, v. 11, n. 128, p. 3-18, 1985.

RESENDE, M. N.; CURI, N.; REZENDE, S. B.; CORRÊA, G. F. Pedologia: base para distinção de ambientes. Lavras: UFLA, 2007. 322 p.

SÁ, C. F. C. Regeneração em área de floresta de restinga na Reserva Ecológica Estadual de Jacarepiá, Saquarema, RJ: I., estrato herbáceo. Arquivos Jardim Botânico do Rio Janeiro, Rio de Janeiro, v. 34, n. 1, p. 177-192, jun. 1996.

SILVA, A. C.; LIMA, J. M.; CURI, N. Relação entre voçorocas, usos da terra, solos e materiais de origem na região de Lavras, MG. Revista Brasileira de Ciência do Solo, Campinas, v. 17, n. 3, p. 459-464, set./dez. 1993.

SILVA JÚNIOR, R. L. Variabilidade espacial do índice de cone correlacionada com mapas de produtividade.
2001. 132 p. Dissertação (Mestrado em Agronomia) - Escola Superior de Agricultura Luíz de Queiroz, Piracicaba, 2001.

SIQUEIRA, L. P. Monitoramento de áreas restauradas no interior do estado de São Paulo, Brasil. 2002. 116 p. Dissertação (Mestrado em Recursos Florestais) - Escola Superior de Agricultura Luiz de Queiroz, Piracicaba, 2002.

SOIL SURVEY STAFF. Soil survey manual. Washington: USDASCS, 1993. 437 p. (Handbook, 18).

STOLF, R. Teoria e tese experimental de fórmulas de transformação dos dados de penetrômetro de impacto em resistência do solo. Revista Brasileira de Ciência do Solo, Campinas, v. 15, n. 3, p. 229-235, set./dez. 1991.

STOLF, R.; FERNANDES, J.; FURLANI NETO, V. L. Recomendação para o uso do penetrômetro de impacto modelo IAA/Planalsucar-Stolf. Piracicaba: IAA/Planalsucar, 1983. 9 p. (Série Penetrômetro de Impacto. Boletim técnico, $1)$.

SUN, D.; DICKINSON, G. R.; BRAGG, A. L. Direct seeding of Alphitonia petriei (Rhamnaceae) for gully revegetation in tropical northern Australia. Forest Ecology and Management, Amsterdam, v. 73, n. 1/2, p. 249-257, Apr. 1995.

UHL, C.; BUSCHBACHER, R.; SERRÃO, E. A. S.

Abandoned pastures in Eastern Amazonia: 1-patterns of plants succession. Journal of Ecology, Oxford, v. 76, n. 3, p. 663681, Sept. 1988

VIEIRA, C. M.; PESSOA, S. V. A. Estrutura e composição florística do estrato herbáceo-subarbustivo de um pasto abandonado na Reserva Biológica de Poço das Antas, município de Silva Jardim, RJ. Rodriguésia, Rio de Janeiro, v. 52, n. 80, p. 17-30, 2001. 